\title{
Post-growth perspectives: Sustainable development based on efficiency and on sufficiency
}

RUDI KURZ, Prof. Dr.*

\author{
Article** \\ JEL: B52, D01, E23, O3, O44, P18, Q01, Q54 \\ https://doi.org/10.3326/pse.43.4.4
}

\footnotetext{
* The author would like to thank the two anonymous referees and guest editors of this journal for helpful comments on the paper. The author did not receive any financial support for the article.

${ }^{* *}$ Received: August 18, 2019

Accepted: October 8, 2019
}

\section{Rudi KURZ}

Pforzheim Business School, Tiefenbronner Str. 65, D-75175 Pforzheim

e-mail: rudi.kurz@hs-pforzheim.de

ORCiD: 0000-0003-1212-6076 


\section{Abstract}

With the United Nations Sustainable Development Goals (SDGs) and the Paris Agreement the general idea of sustainable development has been transformed into a policy concept with well-defined goals, indicators for measurement and an implementation process. To reduce environmental impact (e.g. on climate, SDG 13) two basic options are available: efficiency and sufficiency. Eco-efficiency (less environmental impact per unit of GDP) still plays the most important role and has the potential to delink economic growth and environmental impact. Growth could continue (green growth). However, rates of efficiency increase are not (yet) large enough to comply with e.g. climate goals - and efficiency increase is (partly) compensated by rebound effects. Therefore, greater emphasis on the sufficiency option (lower GDP) is necessary, i.e. consumption patterns and lifestyles will have to change; in macro-economic terms: economic growth (in rich countries) will have to end. This has significant consequences for the transformation of economies and societies and for government policies, which have been dominated by growth policy. Nevertheless, given the ambitious environmental (climate) goals and the only small effects of efficiency strategies, strengthening of the sufficiency option is inevitable. Only with policy concepts that integrate the efficiency and sufficiency components is there a chance to fulfill environmental SDGs - which are the foundation for many other SDGs.

Keywords: delinking, GDP, green growth, happiness, IPAT equation, rebound effect, secular stagnation, transformation

\section{INTRODUCTION}

After almost three decades of intensive global debate on sustainable development the year 2015 changed the scene fundamentally. What the Brundtland-Report (WCED, 1987) and the two Rio Summits in 1992 and in 2012 had prepared, culminated in two global agreements: the UN Agenda 2030 with the SDGs and the Paris Agreement on Climate Change. The sustainable development debate has a new quality now; it has been transformed into a political commitment with welldefined common goals, indicators for measurement and an implementation process. The core features of the "future we want" (UN conference Rio+20) are clear.

This progress was overdue. Alarming reports from the IPCC (2018) on climate change and the IPBES (2019) on biodiversity loss were complemented by "empirical evidence" that everybody can experience without complex measurement methods: weather extremes (heatwaves, droughts, floods, storms and wildfires) and the disappearance of formerly common species (bees, butterflies and so on). The global ecological crisis seems no longer far away, rather, mankind is already in the middle of it.

While climate change (SDG 13) and - to a lesser extent - biodiversity loss (SDGs $14,15)$ are in the focus now, sustainable development is more complex and has to address more (conflicting) goals. Environmental goals have to be aligned with 
socio-economic goals - primarily poverty reduction (and the related hunger, health and education goals). Nevertheless, coping with the environmental limitations and goals is considered fundamental to sustainable development. All socioeconomic problem solving will turn out useless if the "solutions" are accompanied with the overburdening of eco-systems and resource bases. Socio-economic problems will then return even more fiercely.

While sustainable development addresses inter-generational justice and respect for future generations, the "old" problems of intra-generational justice did not disappear and are closely interwoven with the inter-generational ones. In a simplified global perspective there is a wealthy billion and there is a billion living in extreme poverty and in between there is a five-billion strong "middle class" coping with a declining hope for upward mobility. As emphasized already in the Brundtland Report (WCED, 1987: 54) the "needs of the present" are "in particular the essential needs of the world's poor" (e.g. the bottom billion). They need more goods, i.e. economic growth (with growth rates of 7\% p.a., see SDG 8).

For the affluent billion the question and the sustainability challenge are very different: "How much is enough"? (Skidelsky and Skidelsky, 2012), is it time to change consumption patterns and lifestyles and to switch from over-consumption to sufficiency? So far, not much attention has been dedicated to this question in economic literature or in government policy in the rich nations. The potential conflict between the dominating economic growth paradigm and environmental SDGs has been resolved by the idea of eco-efficiency and Green Growth (GG). When confronted with environmental and resource limitations, the traditional paradigm of economic growth can prevail as eco-efficiency increases will delink output (Gross Domestic Product GDP) and input (of natural resources).

This article starts with defining and explaining the strategic options for the reduction of environmental impacts (part 2). It will then discuss the concept of ecoefficiency and what this strategic option can contribute to environmental SDGs. This part (3) also addresses the relevance of rebound effects. The subject of part 4 is the sufficiency option, both micro-economic (consumption patterns) and macroeconomic aspects (secular stagnation). In part 5 some conclusions are presented and it is argued that only a combination of the efficiency and the sufficiency option has a chance to meet ambitious environmental SDGs. The focus in this article is on rich, developed countries only (as e.g. organized in the OECD). This is not a homogeneous group, but no differentiation between countries is made here. Most examples focus on climate change (SDG 13) because this is the most urgent and most elaborated of the SDGs. The most relevant socio-economic goal is economic growth (as measured by GDP) and therefore the growth paradigm is of special interest here. 
2 STRATEGIC OPTIONS FOR SUSTAINABLE DEVELOPMENT:

EFFICIENCY AND SUFFICIENCY

\subsection{THE NORMATIVE STARTING POINT}

Economic analysis starts with political goals which are defined in political, democratic processes by parliaments. Economists then provide advice and recommendations about how to achieve these given goals effectively and efficiently. In the case of climate change (SDG13) the goal has been formulated as a consequence of the legally binding Paris Agreement to limit global temperature increase to $2^{\circ} \mathrm{C}$, better $1.5^{\circ} \mathrm{C}$ only (compared to pre-industrial time). The question for science (economics) is how to decarbonize the economy by 2050 globally? The EU has formulated this goal (EU Commission, 2018). Rich countries like Germany lag behind: minus $80-95 \%$ by 2050 (relative to 1990), i.e. "almost" decarbonized. The expectation would be that rich countries play a pioneer role and decarbonize well before 2050. Climate science provides information on the additional quantity of $\mathrm{CO} 2-$ emissions that are (with high probability) compatible with the $1.5^{\circ} \mathrm{C}$ goal. There is a "carbon budget" of roughly 800 gigatonnes (Gt) CO2-emissions (IPCC 2018). For a world population of 8 billion this equals 100 tons per capita - under the (normative) assumption that each person should have an equal share of the carbon budget. This means: neglecting the historical burden that early-industrialized countries like the UK and Germany had already accumulated over the previous 150 years. For Germany with about 80 million inhabitants (1\% of the world's population) under the equality assumption the national carbon budget is $8 \mathrm{Gt}$. Given the annual emissions of about 800 million tons, the German budget would cover ten years. Only radical reduction steps could extend this to 20 years. Every year 40 million tons have to be eliminated and Germany has to be carbon neutral by 2040 (Kurz, Spangenberg and Zahrnt, 2019).

\subsection{TWO COMPONENTS}

When the environmental goal is given, strategic options for compliance can be discussed next. The starting point is the simplest version of decomposing environmental impact I by an extension of the identity I = I:

$$
\mathrm{I}=\mathrm{I} / \mathrm{GDP} * \mathrm{GDP}
$$

Impact I is determined by two variables: GDP is a measure of the production (output) of an economy. I/GDP is the eco-efficiency of the economy and measures how much environmental impact is caused by producing one unit of GDP. The reciprocal GDP/I is productivity, i.e. how much GDP is produced with one impact unit (e.g. one tonne of $\mathrm{CO} 2$-emissions). This is the standard definition in economics primarily used for labour productivity: GDP/worker. For more specific ecoefficiency indicators e.g. in a business context see UN (2009).

If GDP increases (economic growth), environmental impact I will increase too, all other things being equal. However, if I/GDP declines, I may decline - even if GDP grows. The variables I and GDP are then "delinked" (decoupled). With an 
eco-efficiency increase, economic growth can continue while at the same time environmental impact is reduced.

Here are some examples which have been discussed in the literature and have some political relevance:

(a) Factor 4: (Weizsäcker, Lovins and Lovins, 1997): If over a period of 20-30 years eco-efficiency were to quadruple, GDP could double (grow at 2-3\% p.a.) and yet I could be reduced by $50 \%$.

$$
\begin{gathered}
\mathrm{I}=\mathrm{I} / \mathrm{GDP} * \mathrm{GDP} \\
1 / 2=1 / 4 * 2
\end{gathered}
$$

This would require an increase of eco-efficiency of 4-5\% p.a.

(b) Factor 3: A GDP growth rate of 2\% p.a. would increase the GDP by roughly $50 \%$ in the period $2020-2040$. If the environmental protection goal is to reduce impact I over that period by $50 \%$ the formula reads:

$$
1 / 2=\mathrm{I} / \mathrm{GDP} * 1.5=1 / 3 * 3 / 2
$$

Eco-efficiency has to increase by a factor of 3, i.e. to produce one unit of GDP in 2040 only a third of the resources (emissions) of 2020 are required. This implies an annual increase of eco-efficiency of more than 5\%. So far, there is no empirical evidence that such high efficiency increase rates are possible over many years. Most OECD countries show rates of 1-2\% p.a. (Kurz, 2014). An "efficiency revolution" would be necessary, i.e. a doubling of efficiency growth rates.

(c) Factor 20: Climate policy goal in Germany is to reduce CO2-emissions by $80-95 \%$ in the period $1990-2050$, i.e. up to "factor 20 ". This requires an increase of $\mathrm{CO} 2$-efficiency of $3 \%$ p.a. ( $80 \%$ goal) or even more ambitious $5 \%$ p.a. $(95 \%$ goal). Again the problem is, that the trend of efficiency increase is much lowerand hence climate policy goals are missed (as for 2020).

Such results were calculated and formulated by PwC in 2012: "The global economy now needs to cut carbon intensity by $5.1 \%$ every year from now to 2050 to achieve this carbon budget. This required rate of decarbonisation has not been seen even in a single year since the mid-20th century when these records began."

\subsection{IPAT EQUATION}

A more general formula and an extension is the so called IPAT equation (introduced in the 1970 s by B. Commoner, P. R. Ehrlich and J. Holdren et al.):

$$
\mathrm{I}=\mathrm{I} / \mathrm{GDP} * \mathrm{GDP} / \text { person * persons }
$$


There are three components now, highlighting three strategic options for the reduction of environmental impact I:

- I/GDP: reduction of the impact per unit of output (GDP), i.e. eco-efficiency.

- GDP/person: reduction of income per person, which is related to a reduction of consumption expenditure, i.e. sufficiency (in the rich countries). How much income and consumption are enough?

- Persons: Decline of (world) population could contribute to a lowering of I. This strategic option will not be addressed here as it is not a core variable for sustainable development in rich countries over the next two decades.

Applied to climate change the IPAT-formula reads:

$$
\mathrm{CO} 2=\mathrm{CO} 2 / \mathrm{kWh} * \mathrm{kWh} / \mathrm{GDP} * \mathrm{GDP} / \text { person } * \text { persons }
$$

The goal of reducing $\mathrm{CO} 2$-emissions could be compatible with economic growth, if carbon intensity of the energy system $(\mathrm{CO} 2 / \mathrm{kWh})$ and / or energy efficiency of the economy (kWh/GDP) declined. However, ambitious decarbonization goals (e.g. by 2040) will not be achievable in a growing economy. Growth will "consume" efficiency increases and energy demand will not decline. If energy demand doesn't decline it will not be possible to provide enough energy from renewable (CO2-free) sources - unless the installation of renewable capacities (including grid infrastructure and storage capacity) is accelerated dramatically - with high material and land resource consumption, i.e. shifting the (climate) problem to other goals of sustainable development. The solution is: reduction of $\mathrm{CO} 2$ per unit of GDP by $50 \%$ and switching to renewable sources for the remaining $50 \%-$ without growth of GDP (Kurz, Spangenberg and Zahrnt, 2019). A decline of population would allow for increases of GDP/person.

\subsection{IPATH EQUATION}

GDP is an output measure and a measure of annual incomes. It is not an appropriate measure beyond this narrow scope. GDP and especially GDP/person have been used as a proxy for standard of living, well-being and happiness $\mathrm{H}$. This has been criticized in many publications (Stiglitz, Sen and Fitoussi, 2009). Nevertheless, the core goal of economic policy at least since WW II has been to increase of peoples' incomes (growth policy). Based on the IPAT-equation this would have to be reversed: reduction of per capita income is identified as a potential contribution to the reduction of environmental impact. An extension of the IPAT formula provides additional insight:

$$
\mathrm{I}=\mathrm{I} / \mathrm{GDP} * \mathrm{GDP} / \mathrm{H} * \mathrm{H} / \text { person } * \text { persons }
$$

Impact $=$ Technology $*$ Affluence $*$ Happiness $*$ Population 
This equation could be called the IPATH equation. It highlights a fourth component for impact reduction: GDP/H is the expenditure for market-based goods and services needed per "unit of happiness". This form of affluence has to decline. The challenge is to explore options for happiness (well-being, prosperity) which do not rely on (so much) material goods. Happiness H per person doesn't have to decline. With less expenditure for consumption less income is needed. This provides the opportunity of less paid work and more leisure time - which can be an additional source of happiness. IPATH illustrates the "double delinking":

- delinking type 1 is I/GDP, the efficiency revolution

- delinking type 2 is $\mathrm{GDP} / \mathrm{H}$, the sufficiency revolution

If per capita income increases no more, this is not the end of increasing the "wealth of nations" which has been the explicit promise and job of economics since 1776. This dismal perspective would be unavoidable if income were the only determinant of happiness (well-being). However, this is not the case: end of growth is not end of the pursuit of happiness.

\section{EFFICIENCY, REBOUND EFFECTS AND GREEN GROWTH}

Increase of eco-efficiency is the dominating answer to almost all challenges in the context of environmental sustainability goals: energy efficiency, resource efficiency, land-use efficiency. Ambitious rates of increase in eco-efficiency (e.g. 5\% p.a.) could delink economic growth and environmental impact. This section will analyse the prospects of this option.

\subsection{REBOUND EFFECTS}

The phenomenon is simple and omnipresent: If a product gets more efficient i.e. less resource consuming and hence less costly, this creates an incentive to buy and use more of it. The most famous historical case has been analysed by W. St. Jevons (1866), the Coal Question: "It is wholly a confusion of ideas to suppose that the economical use of fuel is equivalent to a diminished consumption. The very contrary is the truth. New modes of economy will lead to an increase of consumption." The explanation is: "If the quantity of coal used for blast-furnace be diminished in comparison with yield, the profits will increase, price will fall, demand increase... (over-)compensate the initial reduction of coal consumption." This has been called the Jevons Paradox: Increase in resource efficiency may result in an increase rather than a decrease of total resource consumption. The rebound effect involves all economic decision-makers, companies as well as private households (consumers): higher efficiency, lower price, higher demand. Today, there are many more examples:

- While energy efficiency of machines and consumer goods (refrigerator, heating etc.) increases, overall energy consumption does not decline.

- With more efficient light technology (LEDs) nobody is bothering about turning off the lights.

- More fuel-efficient car engines encourage higher powered cars (SUVs), driving more and longer distances. 
- With better insulation of buildings, heating costs decline, higher room temperature is "affordable", and it is not necessary to wear a sweater any more.

$\mathrm{RE}$ are identified by comparing two cases: what would the effect of an efficiency increase be on the quantity of (energy) demand if the price remained constant? Energy demand would then be constant and the higher efficiency would completely reduce overall energy consumption. This hypothetical case is compared with the more realistic case that price declines due to more efficient (cost reducing) technology. The delta is the RE.

If fuel consumption of cars declines from 7 litre per $100 \mathrm{~km}$ to 6.3 this is a $10 \%$ increase of fuel efficiency. The expectation would be that total fuel consumption (and CO2-emissions) will also decline by $10 \%$. If the decline is only $5 \%(1 \%)$ there is a rebound effect of $50 \%(90 \%)$. The "gap" of five percentage points is the result of higher demand for fuel (more and longer rides, faster driving etc.). Half of the efficiency increase is lost, "consumed" by users. If there is no reduction at all $(0 \%)$, the rebound effect is $100 \%$ (full rebound). If there is actually an increase in demand, this is called "backfire".

Efficiency increase has direct and indirect effects and empirical results depend on the scope of analysis. Focus of RE analysis is on the direct, sector-specific effect of a more eco-efficient technology, on lower costs and prices and higher demand (e.g. more fuel efficient cars, demand for fuels). However, price reductions also have an income effect, i.e. lower price is equal to higher (real) income. The savings from the fuel efficient car could also be used for an (additional) flight and hence would not be reflected in the demand for car fuel - an underestimation of the rebound effect. In more general macro-economic terms, eco-efficient technologies have the potential to stimulate overall GDP-growth ("green growth") which is related to all kinds of additional natural resource consumption (macro rebound). The new technology also comes with its inherent eco-impacts, e.g. e-cars depend on critical resources for batteries; more efficient buildings "consume" (additional) insulation material. These effects throughout the (global) supply-chain would have to be included in a complete analysis of RE.

Increases in eco-efficiency are part of the economic innovation process. They are typically the result of cost-intensive R\&D activities and innovators will try to charge a high price to cover these costs and to earn an (extra-ordinary) profit as a reward for their successful research efforts. It will depend on their monopoly power whether the eco-efficient technology comes with low(er) prices. Monopoly power could be a constraint on diffusion and hence on rebound effects, at least a temporary effect until barriers to market entry erode. In fact already Jevons' coal question highlights an innovation process: a more efficient steam engine is now attractive for new uses throughout the economy (diffusion); this is the basic reason for higher (coal) demand, not so much the increased demand of incumbents. 
The explanation of RE can be based on standard micro-economics and rational decision making only: lower cost (total cost of ownership) increases demand. Behavioural Economics beyond rational decision making can add some aspects:

- People tend to forget the initial (high) investment cost and make everyday decisions based on marginal cost: the additional cost of the "extra mile" with an efficient diesel car then is calculated as 5 litres $=6 €$ per $100 \mathrm{~km}$; actually, it is roughly $0.30 € / \mathrm{km}$, i.e. $30 €$ per $100 \mathrm{~km}$.

- People "reward" themselves for doing something eco-friendly (moral licensing). Shoppers who bring their own bags to the supermarket tend to buy more sweets, crisps and ice cream. Households that succeed in reducing their water consumption tend to increase their electricity consumption (Karmarkar and Bollinger, 2014).

\subsection{MACRO-ECONOMIC EFFECT: GREEN GROWTH}

Based on optimism about continuous eco-efficiency increases, the concept of "Green Growth" (OECD, 2011; Kurz, 2014; 2019a) develops a positive vision of future growth combined with SDGs compliance. This is still the dominating defence of the growth paradigm in the conflict with the goal of environmentally sustainable development. However, the emphasis of the potential of this solution is not supported by empirical evidence. Nowhere are there cases of efficiency growth rates larger than 5\% p.a. over a longer period of time. To base sustainable development (e.g. climate protection) only on (unpredictable) eco-efficiency increases in the future would be irresponsible. As it is not possible to rule out the existence of a black swan, it is not possible to deny a small probability for GG. However, like black swans, it is a very rare species.

In sum, GG is not a solution as long as the size of greening (substitution effects) is over-compensated by the size of growth (income effects). On a limited planet, economic growth cannot continue forever, not even over the next decades, as there is no evidence that it could be delinked effectively and fast from environmental impacts by dramatic increases of eco-efficiency (efficiency revolution).

\subsection{RELEVANCE OF ECO-EFFICIENCY FOR SUSTAINABLE DEVELOPMENT}

The Jevons Paradox and the analysis of RE are adding to the warning not to overestimate what technology can do for a reduction of environment impacts. Ecoefficiency is not the silver bullet for resolving the conflict between economic growth and environmental SDGs. So far, efficiency increases are not large enough to achieve sustainability goals in growing economies, i.e. growth and sustainable development are incompatible. Either (rich) nations give up their growth policy or they will fail to comply with their SDGs and hence shift incalculable burdens onto their (grand-)children. In other words: Either give up income (perceived as wealth) or give up moral integrity.

The important function of the efficiency option will remain: Technology can buy time, shift an environmental problem from a "hot spot" to what seem to be less 
risky fields, e.g. nuclear and fossil substituted by renewable energy - presumably without any cost (the sun is sending no bills). Eventually it turns out that old risks have been traded against new ones - often no less serious (e.g. the resource problems of e-mobility related to lithium, cobalt and so on). The general efficiency or modernization promise turns out to be flawed. Technology is not a causal therapy, rather a tool for crisis management. It is popular because it is comfortable for (almost) everyone: consumers don't have to change their behaviour, politicians don't have to make unpopular proposals and decisions, companies find new markets (green growth). The more fundamental issue of sufficiency, the limits of consumerism and the limits to growth (Meadows et al. 1972), is much harder to address. As the efficiency revolution loses some of its glamour, sufficiency and de-growth gain attractiveness. The learning spreads that sustainable development is not a technology race but a fundamental reorientation of human and economic development, a cultural revolution.

\section{SUFFICIENCY AND RESILIENCE}

\subsection{BASIC IDEA}

The basic idea of sufficiency has been around for centuries in religious and philosophical contexts: How much is enough? How much is necessary for a good life? Economist from Smith to Mill and to Keynes addressed the issue and the perspectives of increasing wealth by providing more and more consumer goods. Critique of "consumerism" has a long tradition (Veblen, 1899; Galbraith, 1958). The new context today is sustainable development: What level of consumption is possible today (for living generations) without ruining the natural foundations of life for future generations? Formulated as a moral question it runs how can we enjoy our lives at the cost of our grandchildren? Sufficiency is the real core of sustainable development, i.e. development (advancement of socio-economic goals) within the carrying capacity of eco-systems, respecting the environmental limitations (Begrenzungskrise). The question of the limits of natural resource consumption, which started the sustainable development debate in the 1970s, leads to the question of the limits of the production and consumption of goods and services. How much more is possible - given the well-known "side effects" (e.g. on climate change)? After a period of unprecedented increase of material wealth (GDP), the costs and benefits of additional income and consumption have to be re-evaluated. Instead of postponing the sufficiency debate a more proactive attitude is necessary.

Sufficiency addresses the question of how many products and services consumers actually need. Would fewer quantities and less spending reduce consumers' happiness (overall life satisfaction, well-being, utility)? Interwoven but conceptually different from the "less" is the "different" aspect: choosing a different product (e.g. more fuel-efficient car). While most sufficiency debates cover both aspects, the challenge clearly is on the "less / fewer", the "zero option". More efficient ("smart") solutions easily find acceptance - at least in market niches, from smart cars to smart homes, as long as the "less" is avoided. The core sufficiency challenge to the (about 1 billion) rich all over the world with affluent lifestyles is: less 
mobility (fewer kilometres travelled), less energy demand (lower room temperature), less land consumption (smaller apartments). Sufficiency is not identical with Verzicht (renunciation, self-deprivation) - which includes an element of (willingly) suffering and could be beneficial e.g. in a religious context.

Sufficiency is a challenge for individual consumer behaviour and it has significant macro-economic implications. It is a challenge to the core idea of economic growth. Less consumer demand means less production, less investment and a smaller GDP. It causes new economic adaptation and transformation problems which are challenging for theory and for policy.

The sufficiency revolution is more challenging than the efficiency revolution and has the potential of a cultural revolution, a fundamental change of society and economy. It is not just about eating a little bit less meat or flying less. Sufficiency is questioning the whole concept of "pursuit of happiness" by means of increasing the production and consumption of more goods. It is about breaking up the vicious circle of more needs, more income, more (alienated) work, more (compensating) consumption. It constitutes the duty to work against hedonistic consumerism and increasing "flight shame" might be a first success. Refocusing the materialistic system and developing cultural perspectives beyond can rely on many sources - from Fromm (1976, to have or to be) to Illich (1973, self-sufficiency, conviviality). The open question is, whether developed nations will be able to achieve the huge cultural accomplishment of voluntarily imposing limitations on the use of natural resources. This is not impossible as has been demonstrated related to the factor labour (child work, slave work) - and the Paris Agreement (2015) could be another success story.

\subsection{QUANTIFYING EFFECTS}

The difference between a (moderate) business-as-usual growth scenario (plus 2\% p.a.) and a (moderate) de-growth scenario (minus $1 \%$ p.a.) is quite significant: $49+18$, i.e. 67 percentage points. In terms of average annual income: the initial annual income of e.g. $€ 36,000$ either increases to $€ 53,640$ or it declines to $€ 2,520$, a difference of $€ 24.120$. To "digest" and to manage such a swing in perspectives and biographies is unprecedented in the last decades.

\section{TABLE 1}

Economic growth projections, 2020-2040

\begin{tabular}{|c|c|c|c|c|c|}
\hline$\gamma$ & 3 & 2 & 1 & 0 & -1 \\
\hline \multicolumn{6}{|l|}{ Year } \\
\hline 2020 & 100 & 100 & 100 & 100 & 100 \\
\hline 2030 & 134 & 122 & 110 & 100 & 90 \\
\hline 2040 & 181 & 149 & 122 & 100 & 82 \\
\hline
\end{tabular}


What could the sufficiency option contribute to sustainable development? To quantify the potential effects we can focus on the global CO2-emissions of 35 billon tons p.a. (World Bank data) and assume that

- the affluent billion is responsible for roughly half of it, i.e. has emissions of 17 t per capita p.a. (e.g. US 16.5 t/capita; Germany 9 t/capita);

- the rest of the world population (6 billion people) has $3 \mathrm{t}$ per capita p.a. (e.g. India 2 t/capita);

- the affluent billion succeeds by 2050 to make a $50 \%$ reduction in their consumption (and incomes) - and as a consequence in their per capita CO2-emissions.

Global CO2-emission would decline by 8.5 billion tons p.a., from 35 billion tons p.a. today to 26.5 billion p.a., i.e. a $24 \%$ reduction of total global CO2-emissions. If reductions of $80-90 \%$ are necessary for the $<2{ }^{\circ} \mathrm{C}$ goal, and if we assume an efficiency factor 4 ( $=75 \%$ reduction), sufficiency could close the gap. If the efficiency effect is smaller, sufficiency is even more important. In this scenario the $50 \%$ reduction of consumer spending is extremely ambitious and the question is what could make such an option attractive to the affluent?

Could "less" really be an attractive perspective for a majority of people? A little bit less seems to be attractive - at least if the success of publications on "simplify your life" is accepted as an indicator. It is doubtful whether significantly less would find any public support. Would anyone join an initiative to reduce consumption expenditures by $1 \%$ every year over a period of 20 years (i.e. roughly $20 \%$ in total)? How many would subscribe to the idea " $50 \%$ less"?

So far, sufficiency still has niche status, identified in empirical studies e.g. as LOHAS (lifestyle of health and sustainability), LOVOS (Lifestyles of Voluntary Simplicity) or labelled as "downshifting" or "minimalism". However, public attention seems to increase. Companies did spot the trend and integrate it in their advertisement (not always in their strategy). There are many projects organized by civil society organizations (like repair cafés, urban gardening). The young generation is asking for work-life-balance and is willing to give up income in order to raise kids. Mobility patterns are changing, urban citizens own no car (don't even have a driving license) and flight shame is often mentioned. Consumption of vegetarian and vegan food is on the rise. New forms of living together are being tested. The environmental impact of such elements of new lifestyles is hard to measure. So far, it seems the overall effect is not significant: mobility is increasing (although it is smarter); the average size of an apartment increases (as the number of single households increases). In sum: there is change in niches, high creative potential, some "business cases" - and ample opportunity for more. More creative solutions will emerge, all demonstrating that sufficient lifestyles are not equal to renunciation and are not a barrier but a promising way to the pursuit of happiness. 
A macro consequence of a continuously declining consumer demand could be economic stagnation or even decline. This depends also on the other components of demand: investment In, government spending $\mathrm{G}$ and trade balance (Ex-Im):

$$
\mathrm{GDP}=\mathrm{C}+\mathrm{In}+\mathrm{G}+(\mathrm{Ex}-\mathrm{Im})
$$

When consumer demand declines, investment will follow suit. With a declining GDP, tax revenues and hence government spending will decline (permanent deficit spending ruled out). Exports could compensate for all this. Together with an expected decline of imports (closely related to economic activity), this will create a large surplus in the trade balance. Other countries will have to run a deficit - and will not accept this long-term. If secular stagnation is the long-term perspective (Summers 2016), the second interesting question is related to the adaption process: How to make this a smooth adaption rather than a cumulative downward spiral? There is little knowledge concerning or research into designing such a process.

Other stagnation effects are transferred via labour markets (supply side): If individuals consume less, they need less income and hence could reduce worktime (enjoy more leisure time). If labour supply declines, various effects will compensate for this: increasing wages, automatization, global supply chains. In some segments (with specific high qualifications) labour supply could become a bottleneck and restrict growth. More leisure time could be invested in community projects and thus increase social capital.

Keynes' (1930) vision was that within a century, average people could reduce working hours to 15 hours per week. This forecast is based on

$$
\text { GDP }=\text { GDP/hour } * \text { hours/worker } * \text { workers }
$$

If labour productivity (GDP/hour) grows at 2\% p.a. over 100 years, it would easily be possible to reduce labour time for a given number of workers producing a constant GDP to 15 hours/worker. But why is everyone still working much longer (e.g. 35 hours/week in Germany)? Obviously workers were not satisfied with their income (GDP) as of 1930. Most of the efficiency gains were thus used for higher incomes and consumption levels. And this is still the situation: productivity increase can be used for wage increases or for reduction of working hours. Only when workers are satisfied with their income levels, will Keynes' vision be able to unfold its full potential: more leisure time could make people happier.

\subsection{SUFFICIENCY POLICY}

Today sufficiency is primarily an individual search process, testing new consumption patterns, exploring and finding new lifestyles (social innovation). Government policy is not supportive as it is focused on fostering the innovation and growth process, the increase of GDP/capita as the only relevant indicator for economic wealth. Without a systematic and consistent government policy, sufficiency 
will have little effect. Research on and implementation of sufficiency policy is the next crucial step for sustainable development.

Sufficiency is a challenge not only for individual decision making but also for political decision making on the framework conditions that are always a determinant in consumers' decision making. A government sufficiency policy could enable and incentivize consumers. However, no consistent concept has been formulated yet. It has to steer clear of paternalism and eco-dictatorship. It would be naïve to leave it to individuals alone to change their decisions without addressing the political framework conditions which influence these decisions. Well-intentioned moral behaviour will finally surrender to hostile circumstances. The legal and institutional framework has to be favourable for moral decision making. Moreover, if consumers had to include a complex, multi-dimensional goal system like the UN SDGs in their decision making, they would be hopelessly overburdened. Complexity reduction and translation is necessary.

The first step could be to stop all forms of growth policy: Abolish all growthstimulating measures e.g. in the tax code, revise deregulation, no unspecific subsidies for R\&D. Laws that define growth as goal for government policy should be abated. Government expenditure has to be restructured, e.g. infrastructure investment: no new roads, runways and terminals - bike lanes and public transportation instead. Environmental restrictions have to be "translated" in regulations and concrete caps e.g. parking lots, runway slots.

The next step is to develop a holistic concept of a sufficiency policy that includes (almost) all fields of government policy, at least check their relevance and the effectiveness of potential changes. Following the conventional list of economic policy instruments this creates the following list:

(1) Information: Reduce complexity by creating / supporting reliable labels (fair trade, FSC etc.). Support for traditional consumer protection organization should be redirected to include sustainability issues. Results of behavioural economics on (irrational) consumer behaviour provide new approaches (nudging).

(2) Education: Consumer behaviour and decision making have little connection with those of the autonomous textbook individual. Preferences are formed as part of the industrial production process. Education could contribute to make individuals more independent of status and consumer goods and strengthen their personal capabilities.

(3) Voluntary agreements: Companies often claim a pioneer role in sustainability and Corporate Social Responsibility (CSR) and could voluntarily do more beyond reporting, especially in their product policy (longevity vs. obsolescence).

(4) Government spending (purchasing behaviour, lead customer), infrastructure investment (bike lanes and public transportation instead of autobahns), social safety net (basic income). 
(5) Prices could be a simple indicator for sustainable consumption and change consumer decisions significantly - if only they told the (ecological and social) "truth". Government can correct market prices by taxes and subsidies. Alternatives are cap-and-trade systems.

(6) Regulation (command and control) always seems to be the ultima ratio. However, this instrument has significant advantages as it relieves individuals from the burden of decision making, is fair (equal for everyone) and effective. Examples: fuel-efficiency standards, phase-out of fossil car engines.

\section{PERSPECTIVES AND POLICY RECOMMENDATIONS}

To achieve ambitious SDGs, e.g. carbon neutrality by 2040, both strategic options - efficiency and sufficiency - have to be activated and strengthened. What would be the core elements of efficiency policy and of sufficiency policy and how can the two be integrated (transformation planning)?

\subsection{INCREASE ECO-EFFICIENCY GROWTH RATE}

The challenge is to stimulate and to redirect innovation activity into an eco-efficient direction. Government policy has only limited influence on innovation activity (e.g. Steger et al. 2005; https://ec.europa.eu/environment/ecoap/frontpage_en on EU eco-innovation policies). The most general tool is to change expectations of entrepreneurs and investors. Government and civil society organizations together have to stimulate a public debate on "the future we want". This influences strategies and direction of search activities (e.g. the climate debate and new mobility solutions). In more detail, eco innovation policy could combine a set of instruments:

- Government R\&D expenditures (from basic research to market entry and diffusion) for "green" technologies and market segments (e.g. wind and solar energy). Redirect science system in general (WBGU, 2011).

- Price signal (e.g. taxing negative external effects of CO2-emissions) and financial incentives (e.g. favourable depreciation rules) to make (eco-) investments more attractive i.e. profitable (e.g. in renewable energies).

- Technology forcing by regulations, e.g. ambitious fuel-efficiency fleet standards. Forced phase-out of hazardous and/or polluting technologies (e.g. coal-fired power plants).

\subsection{REDUCE REBOUND EFFECTS: CONTROL OF PRICE REDUCTIONS AND/OR DEMAND}

$\mathrm{RE}$ can be directly addressed and reduced if either the cost and price reductions are eliminated or the potential expansion of demand (quantity) is restricted. To eliminated the decline of prices, a (eco-)tax could be introduced - with tax rates increasing with the rate of eco-efficiency growth (and tax revenue spend for eco or social goals). This could be e.g. a CO2-tax with eco-bonus. The same function could be fulfilled if real incomes could be reduced when people work less and enjoy more leisure time (reduction of working hours). Most effective would be quantitative restrictions (caps). More efficient (cheaper) fishing technology can cause a decline of fish population. Fishing quotas could avoid this. The EU-ETS 
defines reductions of $\mathrm{CO} 2$-emissions - no matter what eco-efficiency does; efficiency increases are crucial for the price of certificates, i.e. the cost for companies and society. Other regulations include e.g. in the mobility sector limitation of car "horsepower" and/or speed limits (so that it makes less sense to buy high-powered cars). Parking restrictions for SUVs instead of additional (larger) SUV parking lots and/or general reduction of parking space. In sum, there are policies capable of reducing the RE but these are neither popular nor easy to enforce.

\subsection{SUFFICIENCY POLICY}

The stability of capitalist systems is based on the old recipe developed by Adam Smith (1776): increase the supply of goods and keep people busy. To keep people satisfied, a permanently increasing quantity and quality (innovation) of goods is necessary and people need to have jobs - to finance consumption and to structure their life time. Under these conditions the system works well and is stable. Only recently has there been more attention to the question of whether this logic will prevail. Being trapped in the work-consumption-circle is no longer a generally shared vision and this type of "social contract" is losing its attraction the wealthier nations and individuals get. Mill (1848) and Keynes (1930) recognized this and they emphasized the positive aspects. Today there is ample empirical evidence that beyond a certain level of income, further increase of income and consumption will not increase well-being and happiness (Easterlin 1996; Frey, 2008).

To make it acceptable for a majority of voters, sufficiency has to be attractive, i.e. it has to fulfil a (basic) need. In rich societies the basic material needs are fulfilled (on average). However, there are more sophisticated needs which play a more vital role. People are interested in non-materialistic "products" like social responsibility, making sense of their life, personal integrity. Of course, there are mechanisms to compensate for deficiencies in these dimensions. An increasing entertainment industry is supportive in distracting attention from such (potential) needs. And human beings have learned to live with "cognitive dissonance", i.e. knowledge is not necessarily transformed into action. However, with increasing knowledge and awareness about environmental degradation and the burdening of future generations, these expulsion mechanisms become fragile. More often people tend to act - at least with alibi consumption (some fair-trade products, biofood, sometime vegetarian meals, e-bike). This need is also served by joining demonstrations (e.g. against climate change, F4F). It is in this context that a consistent and effective sufficiency policy could find (many) supporters. It offers a way out of individual moral dilemmas.

Even if sufficiency is attractive to individuals it will not easily be transformed into sufficiency policy. Resistance comes from companies which invest heavily in advertisements to stabilize demand for their products, turning "insatiable needs" from a textbook assumption into a reality. In fact, there is a (global) homogenization of (western) lifestyles and popular culture (Ritzer, 1993) driven by communication technology and the urbanization trends. Children grow up more in virtual 
realities than in nature. The competition-driven innovation system throws out "new" products every day, often just minor (incremental) changes and "fashions". Innovation is celebrated without realizing the dark side of "creative destruction" (Schumpeter 1911), the premature obsolescence of perfectly functioning products (Kurz, 2015). Consumers are locked-in with the old products (stranded assets).

In sum, the basic challenge (in rich countries) is to correct expectations and to establish a "new normal", i.e. to foster cultural change, the mental infrastructure for soft landing after the growth age.

\subsection{TRANSFORMATION DESIGN AND POLICY}

The SDGs are an expression of a changing value system and they change the goal system and the priorities in society and economy. Environmental and social goals define new limitations for economic expansion. In macro-economic terms, the challenge is to manage the transformation process at the end of an almost hundred year period of economic growth (Gordon 2016). How is a soft landing to be designed (Victor 2008)? This challenge has a long-term component, replacing the growthfocus by a more open development concept. And it has a more medium-term component, the formulation of a transformation strategy for the next two decades.

The main challenge for de-growth policy is to avoid "overshooting" reaction of the system, i.e. a self-feeding crisis (economic tipping point) with huge losses for all (like the financial crisis of 2008). Traditional crisis intervention mechanisms (monetary and fiscal) could do the job.

Intra-generational justice under de-growth conditions means more redistribution of incomes and wealth. As vulnerable groups (low-income households) have to be protected from decline of income, higher income groups will have to pay more taxes. How will the privileged react? Do the lucky ones in the lottery of life understand their responsibility and are they willing to share (more) with the less privileged? As conflict potential increases, investment in social capital (inclusion, participation, dialogue and conflict resolution mechanisms) is vital and required today. The better prepared it is, the less painful will the birth of a post-growth society be.

During the transition to sustainable development, economy and society will face a fast and comprehensive structural change including the decline of old (still successful) industries (like the automobile) and regions as well as (global) supply chains and patterns of specialization. The dramatic structural change needs reliable definition of goals, e.g. a deadline for nuclear power, for coal-fired power plants, for fossil-fuel cars. Transition planning also has to include stimuli and compensation measures to make structural change more acceptable for people affected.

Pressure increases for all groups. Different qualifications and skills are needed, often with lower payment and status, sometimes at different locations (dislocation). Overall uncertainty is increasing with only a vague hope for a better future. 
Starting from a quite comfortable status quo, defence of this status and aversion to change are plausible. During the transformation process all forms of resistance will occur (in companies, in the political arena). Transition design and management will be crucial and have to be based on resilient and reliable institutions (schools, education, science, media, courts, police).

Companies are used to a growth world and have no idea how to thrive in a nogrowth environment - where average entrepreneurial talent might not be enough: Exemptions are e.g. Patagonia with their "don't buy!" campaign, referring to the sufficiency idea (https://www.patagonia.com/blog/2011/11/dont-buy-this-jacketblack-friday-and-the-new-york-times/). What could government do the better to prepare companies and managers for a no-growth world? More competition or more cooperation? Higher profits to kindle entrepreneurial spirits? More venture capital for start-ups?

To avoid disaster, design of the transformation process is necessary. Although detailed planning is not possible, at least some key features could be the subjects of government planning and supporting policies. Core elements of transformation design are:

- Strategic planning with implementation process (plan-do-check-act, PDCA).

- Principles and financial resources for burden sharing (compensation).

- Institutions for discourse and conflict resolution.

One example for discourse based transformation planning in the context of climate protection is the coal phase-out in Germany (Kohleausstieg): phase-out of all coal-fired power plants by 2038 - with government compensation payments and regional adaptation programs (in total 40 billion $€$ ). However, this example covers a small industrial segment (some 20,000 jobs). Much more complex (and expensive) will be the transformation of the German automobile industry (with more than 800,000 jobs). No accompanying transformation policy for this industry has been formulated. Other sectors of the economy will also come under heavy adaptation pressure as a consequence of a reinforced efficiency and sufficiency policy: the chemical industry, agriculture, housing and construction.

\subsection{PERSPECTIVE: POST-GROWTH SOCIETY}

Based on the global consensus on the UN SGDs, especially on climate change (Paris Agreement), and commitments formulated in national sustainable development strategies, the growth paradigm is under pressure. As the SDGs address overconsumption of natural resources and over-burdening of future generations, reductions are an unavoidable consequence. "Delinking" would be a (comfortable) way out: more output (GDP) with less input (resources), i.e. an eco-efficiency revolution. But this is just a hypothetical case and is not backed by empirical evidence. If an eco-efficiency revolution does not do the job, growth is not compatible with sustainable development. To reduce environmental impact, production and consumption have to be reduced, i.e. GDP growth is no longer possible. It is necessary 
to study (and to implement) de-growth. This is not just a little technical change of a few percentage points, e.g. instead of plus $2 \%$ p.a. in the past, minus $1 \%$ in the future. This is the end of the growth paradigm, which has dominated economics and all fields of policy on a global scale after WW II. In fact, the challenge is to formulate a new paradigm for the post-growth era. Research on de-growth and on the post-growth paradigm is therefore of increasing importance. But it is difficult and time-consuming to replace an established paradigm (Kuhn, 1962).

The growth paradigm no longer provides convincing answers to the core problems of today. The new paradigm for the post-growth-era could start by replacing "growth" by the more open concept of (economic) "development" - as outlined by Schumpeter (1911). The core idea is economic development as an open decentralized search process without an orientation to growth but emphasizing permanent, sometimes disruptive change and transition processes, which could be cumulative and destructive or rather smooth (by design).

Under the conditions of the Anthropocene, future development has to respect (planetary) boundaries (Rockström et al. 2017), i.e. it has to be "sustainable development". To comply with environmental goals like climate-neutrality by 2040 most rich countries will have to reduce the scale of their economic activity and consumption patterns (de-growth). The process of transition to sustainable longterm level and structure could be painful with increasing conflict potentials and not very attractive to consumers, companies and voters. It is a farewell to the wealth promise as we knew it: more, bigger, faster. As incomes will decline rather than increase, additional wealth and well-being has to come from different sources, pursuit of happiness redirected: labour conditions, leisure time, fairness, inclusion and participation. This is no less than a cultural revolution, one that is already emerging, although in niche projects only (repair cafés, urban gardening etc.).

The micro foundation of de-growth is sufficiency, i.e. lifestyles and consumption patterns which emphasize "less" in all fields of consumption (from mobility to housing and food). If consumer demand declines, investment will follow and the emerging development pattern then could be characterized as "secular stagnation" or "stationary state". In fact, sufficiency is the core of the sustainability debate as it addresses limits and limitations (Begrenzungskrise). Sustainable development is not possible without limitations of production and consumption, i.e. fundamental changes in lifestyles (of the rich). This is not the end of the pursuit of happiness and increasing well-being (Jackson 2009). However, fundamental learning and a process of change (social innovation) are necessary, and they are much less comfortable and welcome than fascinating new technologies. Individuals tend to defend their comfort zone and resist a painful learning process.

Could a Post-Growth-Society be attractive, win voters' support? This depends first of all on problem awareness. Do (many) people understand that their lifestyle is damaging the planet and burdening future generations? Sufficiency and 
de-growth are then welcome as a "pain relief" and there is willingness to pay a price. After all, this price is not exorbitantly high for two reasons: For wealthy people additional income is not highly attractive (marginal utility almost zero); future costs of inactivity would be even higher (for climate change Stern, 2006). As illustrated already by Mill (1848) and Keynes (1930) a stationary state could be a positive vision. However, the visions and images created by the powerful, needs-stimulating advertising-industrial complex drive societies permanently in the opposite direction. The end of the growth age finds rich societies and citizens unprepared. Most people are still in the delirium of the growth party - as the band continues to play on the Titanic.

\section{Disclosure statement}

No potential conflict of interest was reported by the author. 


\section{REFERENCES}

1. Easterlin, R., 1995. Will raising the incomes of all increase the happiness of all? Journal of Economic Behavior and Organization, 27, pp. 35-47. https:// doi.org/10.1016/0167-2681(95)00003-b

2. European Commission, 2018. A clean planet for all. A European strategic long-term vision for a prosperous, modern, competitive and climate neutral economy. COM(2018) 773 final. Brussels: European Commission.

3. Frey, B. S., 2008. Happiness: A revolution in economics. Cambridge, MA \& London: MIT Press.

4. Fromm, E., 1976. To have or to be. New York: Harper \& Row.

5. Galbraith, J. K., 1958. The affluent society. New York: Houghton Mifflin Co.

6. Gordon, R. J., 2016. Rise and fall of American growth: The U.S. standard of living since the Civil War. Princeton; Oxford: Princeton University Press. https://doi.org/10.1111/ehr.12518

7. Illich, I., 1973. Tools of conviviality. New York: Harper \& Row.

8. IPBES, 2019. Intergovernmental Science-Policy Platform on Biodiversity and Ecosystem Services: 2019 Global Assessment Report on Biodiversity and Ecosystem Services. Bonn: IPBES. https://doi.org/10.1111/padr.12283

9. IPCC, 2018. Intergovernmental Panel on Climate Change. Special Report on Global Warming of $1.5^{\circ} \mathrm{C}$. https://doi.org/10.4135/9781483351384.n48

10. Jackson, T., 2009. Prosperity without growth: Economics for a finite planet. London: Earthscan.

11. Jevons, W. St., 1866. The Coal Question. London: Macmillan.

12. Karmarkar, U. and Bollinger, B., 2014. BYOB: How bringing your own shopping bags leads to treating yourself and the environment. Harvard Business School Working Paper, No. 14-065. https://doi.org/10.1509/jm.13.0228

13. Keynes, J. M., 1930. Economic possibilities for our grandchildren. Essays in persuasion New York: W. W. Norton.

14. Kuhn, Th. S., 1962. The structure of scientific revolutions. Chicago: Chicago University Press.

15. Kurz, R., 2014. Green growth and sustainable development. In: R. Moczadlo et al., eds. Regional and international competition - a challenge for companies and countries. Pforzheim, pp. 11-20.

16. Kurz, R., 2015. Quality, Obsolescence and Unsustainable Innovation. Ekonomski Vjesnik, Econviews. Review of Contemporary Business, Entrepreneurship and Economic Issues, 28, pp. 511-522.

17. Kurz, R., Spangenberg, J. H. and Zahrnt, A., 2019. IPCC-Report Global Warming of $1.5^{\circ} \mathrm{C}$ : Das fehlende Szenario "Klimaschutz ohne Wachstum". Ökologisches Wirtschaften, 34(2), pp. 35-39.

18. Meadows, D. [et al.], 1972. The limits to growth. Report to the Club of Rome. New York: Universe Books.

19. Mill, J. St., 1848. Principles of political economy with some of their applications to social philosophy. London: Longmans. 
20. OECD, 2011. Towards green growth. Paris: OECD.

21. PwC PricewaterhouseCoopers LLP, 2012. Too late for two degrees? Low carbon economy index 2012.

22. Ritzer, G., 1993. The McDonaldisation of society. London: Sage Publications.

23. Rockström, J. [et al.], 2017: A Roadmap for rapid decarbonization. Science, 355 (6331), pp. 1269-1271.

24. Schumpeter, J. A., 1911. Theorie der wirtschaftlichen Entwicklung. Berlin: Duncker \& Humblot.

25. Skidelsky, R. and Skidelsky, E., 2012. How much Is enough? Money and the good life. New York, NY: Other Press.

26. Smith, A., 1776. The wealth of nations. An Inquiry into the nature and causes of the wealth of nations: New York: Random House.

27. Steger, U. [et al.], 2005. Sustainable development and innovation in the energy sector. Berlin etc.: Springer.

28. Stern, N., 2006. The economics of climate change (Stern Review). London: Grantham Institute.

29. Stiglitz, J. E., Sen, A. and Fitoussi, J. P., 2009. Report by the Commission on the Measurement of Economic Performance and Social Progress. Paris.

30. Summers, L., 2016. The age of secular stagnation: What it is and what to do about it. Foreign Affairs, 95 (2), pp. 2-9.

31. UN, 2009. Eco-efficiency indicators: Measuring resource-use efficiency and the impact of economic activities on the environment. New York: United Nations.

32. Veblen, T., 1899. The theory of the leisure class. New York: MacMillan Company.

33. Victor, P., 2008. Managing without growth. Slower by design, not disaster. Cheltenham, UK: Edward Elgar.

34. WBGU German Advisory Council on Global Change, 2011. World in transition. A social contract for sustainability. Berlin.

35. WCED World Commission on Environment and Development, 1987. Our common future. New York: Oxford University Press.

36. Weizsäcker, E. U., Lovins, A. B. and Lovins, L. H., 1997. Factor four: Doubling wealth, halvening resource use. London. 